\title{
Optimal Linear Estimation (OLE) Modeling Supports Early Holocene (9000-8000 RCYBP) Copper Tool Production in North America
}

\author{
Michelle R. Bebber (D) and Alastair J. M. Key
}

\begin{abstract}
The discovery and development of metal as a tool medium is a topic of global interest. A fundamental research goal involves establishing the timing of human experimentation with naturally occurring copper ore, which is commonly associated with sedentary, agrarian-based societies. However, in North America, there is well-documented millennia-scale exploitation of copper as tool media by small, seasonally mobile hunter-gatherer groups in the western Great Lakes. Archaeologists have suggested that Late Paleoindian groups may have begun using copper as a tool medium almost immediately after they entered the Lake Superior basin. However, only a few radiocarbon dates support such early use of copper. Here, we use optimal linear estimation modeling to infer the origin date for copper tool production in North America. Our results show that the invention of copper as a tool media likely occurred shortly after the first pioneering populations encountered copper ore during the Pleistocene-Holocene transition. The origin dates modeled here (ca. 8100 RCYBP) reveal several important features about the behavior of pioneering hunter-gatherer populations. Moreover, our results suggest that this phenomenon represents the earliest known use of metal for utilitarian copper tool production.
\end{abstract}

Keywords: copper, North America, hunter-gatherers, Paleoindian, optimal linear estimation, computational archaeology, Pleistocene-Holocene transition, prehistoric metallurgy

El descubrimiento y desarrollo del metal como medio de herramientas es un tema de interés mundial. Un objetivo fundamental de la investigación implica establecer el momento de la experimentación humana con el mineral de cobre de origen natural, que se asocia comúnmente con sociedades sedentarias de base agraria. Sin embargo, en América del Norte, existe una explotación del cobre a escala milenaria bien documentada como medio de herramientas por parte de pequeños grupos de cazadores-recolectores estacionalmente móviles en el oeste de los Grandes Lagos. Los arqueólogos han sugerido que los grupos Paleoindios tardíos pueden haber comenzado a usar el cobre como medio de herramienta casi inmediatamente después de que ingresaron a la cuenca del lago Superior, sin embargo, solo unas pocas fechas de radiocarbono apoyan un uso tan temprano del cobre. Aquí utilizamos un modelo de estimación lineal óptimo para inferir la fecha de origen de la producción de herramientas de cobre en América del Norte. Nuestros resultados muestran que la invención del cobre como medio de herramienta probablemente ocurrió poco después de que las primeras poblaciones pioneras encontraran mineral de cobre durante la transición Pleistoceno-Holoceno. Las fechas de origen modeladas aquí (ca. 8100 RCYBP) revelan varias características importantes sobre el comportamiento de las poblaciones pioneras de cazadores-recolectores. Además, nuestros resultados sugieren que este fenómeno representa el primer uso conocido del metal para la producción de herramientas utilitarias de cobre.

Palabras clave: cobre, Norteamérica, cazadores-recolectores, Paleoindio, estimación lineal óptima, arqueología computacional, transición Pleistoceno-Holoceno, metalurgia prehistórica

Michelle R. Bebber (mbebber@ kent.edu, corresponding author) — Department of Anthropology, Kent State University, Kent, $\mathrm{OH}$, USA

Alastair J. M. Key (ak2389@ cam.ac.uk, corresponding author) — Department of Archaeology, University of Cambridge, Cambridge, UK

American Antiquity 87(2), 2022, pp. 267-283

Copyright (C) The Author(s), 2022. Published by Cambridge University Press on behalf of the Society for American

Archaeology. This is an Open Access article, distributed under the terms of the Creative Commons Attribution-

NonCommercial-ShareAlike licence (https://creativecommons.org/licenses/by-nc-sa/4.0/), which permits non-commercial re-use, distribution, and reproduction in any medium, provided the same Creative Commons licence is included and the original work is properly cited. The written permission of Cambridge University Press must be obtained for commercial re-use. doi:10.1017/aaq.2021.121 
$\mathrm{T}$ The discovery and development of metal as a tool medium is a topic of global interest. Consequently, incipient metal usage is widely studied from multiple archaeological perspectives (e.g., Roberts and Thornton [2014] and references within). A fundamental research goal involves establishing the timing of human experimentation with naturally occurring copper ore (Burger and Gordon 1998; Özdoğan and Özdoğan 1999; Patterson 1971; Roberts et al. 2009) because this phase of development predates other, more complex metallurgical production methods. Prior to the development of smelting and alloying of metals, the forging of native copper was the first method of manufacture used in areas where bronze metallurgy was independently developed. Although in most areas of the world this process of innovation is associated with sedentary, agrarian-based societies, in North America there is well-documented millennia-scale exploitation of copper as a tool medium by small, seasonally mobile huntergatherer groups. This phenomenon is largely associated with Middle-Late Archaic (60003000 RCYBP) cultures located in the Great Lakes region (Bebber and Eren 2018; Ehrhardt 2009; Gibbon 1998; Pleger 2001; Pleger and Stoltman 2009; Vernon 1990). Although it is widely documented that several sites containing copper artifacts date to the latter part of the Archaic period (Hill 2006; Kuehn 2002; Martin 1993; Pleger 2001; Ritzenthaler 1970), there is also a variety of data suggesting that the copper industry in fact began thousands of years prior, during the Early Holocene (Martin 1993, 1999; Pompeani et al. 2013; Reardon 2014; Steinbring 1991; Wittry and Ritzenthaler 1956).

In the second half of the twentieth century, archaeologists documented the possibility that Late Paleoindian groups may have begun using copper as a tool medium almost immediately after they entered the Lake Superior basin (Martin 1999; Steinbring 1966, 1968, 1991). Some have even suggested that Late Paleoindian groups began using copper in southern glacial drift regions well before humans ever set foot in the copper-bearing regions of Michigan's Upper Peninsula (Steinbring 1970). Indeed, reports have shown that Late Paleoindian stone points have been found along with copper tools (Buckmaster and Paquette 1988; Clark 1989, 1991; Hunzicker 2002; Mayer-Oakes 1951; Pettipas 1985) or with unfinished copper fragments (Harrison et al. 1995; Martin 1993; Salzer 1974; Shay 1971), although it is important to note that the exact dates and relationships of the stone and copper materials remain equivocal.

Despite the fact that a strict chronology for North American copper tool evolution is sorely lacking (Bebber 2021; Martin 1993), it is generally thought that the earliest copper tool forms were broadly similar to Late Paleoindian stone point forms, specifically "lanceolate" types related to Plano groups (Pettipas 1985; Steinbring 1975; 1991). Specific styles of copper points (Figure 1), defined as McCreary points (Steinbring 1968), appear to be morphologically analogous to Late Paleoindian projectile points. Unfortunately, as with most North American copper materials, all of these "paleo-like" specimens are poorly dated surface finds (Martin 1999). Due to lack of stratigraphic association and lack of chronometric dating for these specimens, it is difficult-if not impossible - to establish meaningful relationships between them, or to reliably cross-date similarly shaped isolated finds, even when the formal attributes are convincing at first glance. We know from several studies that convergence in projectile point form and technology is quite common (Eren et al. 2018; Maguire et al. 2018; Norris et al. 2019), even on a global scale (Groucutt [2020] and references therein; O'Brien et al. [2018] and references therein; Scerri 2012), and it seems quite sensible that the earliest copper projectiles would be simple in form before ancient people began experimenting with various tang morphologies. Therefore, despite the fact that certain copper points appear to be visually consistent with Late Paleoindian point styles, the argument for their origin remains largely circular.

The understanding of copper development and chronology in North America is currently only as accurate as the artifacts recovered and the sites identified, which ideally includes in situ datable materials and clear stratigraphic and contextual relationships. Unfortunately, for most 

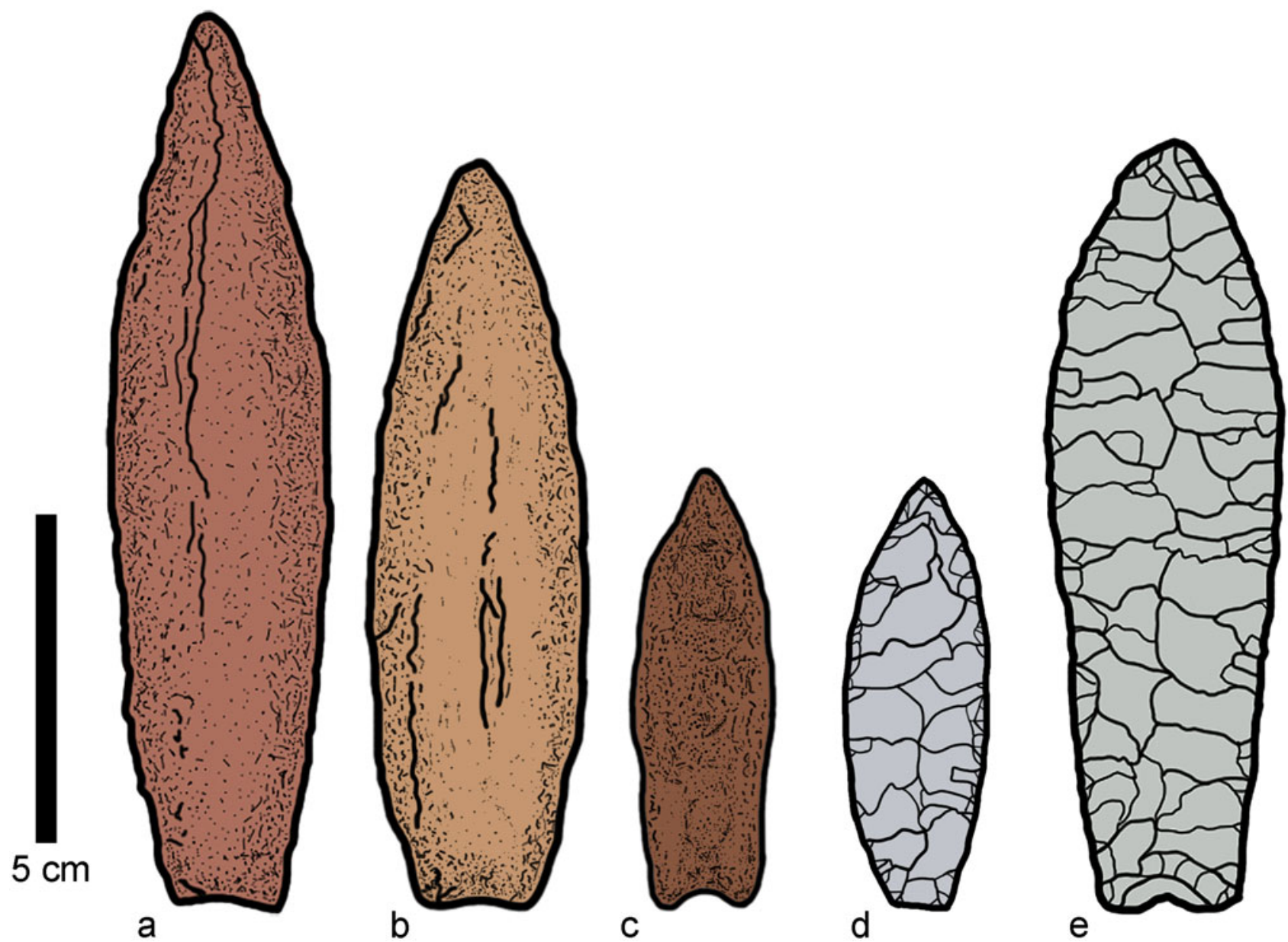

Figure 1. "Paleo-like" copper points and Agate Basin points: Drawn based on (a-b) Steinbring (1968, 1970); Pettipas (1985); (c) Mayor-Oakes (1951), along with typical Late Paleoindian Agate Basin points; (d-e) Steinbring (1970). (Color online) 
copper artifacts, such data are simply not available due to a general lack of systematic fieldwork and the fact that most copper artifacts have been found as isolated surface finds with little provenience data (Bebber and Chao 2022; Martin 1999). Consequently, although intriguing, the data supporting the co-occurrence of Late Paleoindian artifacts and copper materials remain ambiguous.

The copper origin date in North America remains even more uncertain than its later development and chronology due to the fact that chronometric dates demonstrating early use of copper in the Americas are still generally lacking. Yet, recent research has shed light on this topic. Reardon (2014) reported on what was then, and still is, the earliest well-established date for copper tool production and use as hunting weaponry. Radiocarbon dates generated from organic material found embedded in a copper conical point-via use of a metal detector 10$15 \mathrm{~cm}$ (4-6 in.) below the surface in Vilas County, Wisconsin-place copper tool production firmly at $7690 \pm 40$ RCYBP. The second conical point found in the same location generated a similar date of $7305 \pm 60$ RCYBP (Reardon 2014). Likewise, other points from the Western Great Lakes with embedded materials (Pompeani et al. 2021) as well as cremation burial data (Libby 1954; Wittry and Ritzenthaler 1956) provide dates older than 7000 RCYBP (Table 1). Stratigraphic data from the mining region of the Upper Peninsula of Michigan provides the earliest date for a copper production site at $7870 \pm 350$ RCYBP (Martin 1993).

Although these dates are within the range of what is generally considered to be the transition from Late Paleoindian lifeways to Early Archaic tradition in the Western Great Lakes (ca. 10,0008000 RCYBP; Kuehn 2002), there is no definitive archaeological evidence to support the assertion that copper use began soon after the initial occupation of the region by Late Paleoindian groups, which would have occurred sometime after 10,000 RCYBP, and likely much later in the northern copper-bearing regions. A key factor restricting Paleoindian movement into the copper mining district prior to this date was the Marquette readvance of the Laurentide Ice Sheet. This glacial readvance covered the copper-bearing regions of Michigan's Upper

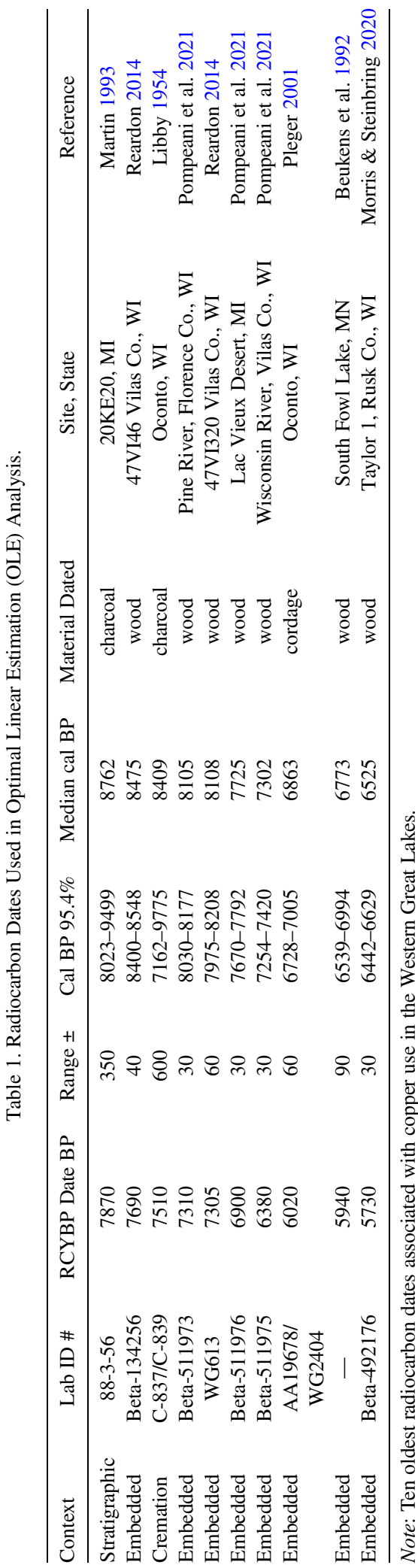


Peninsula until 10,024 RCYBP, at which point it reached its maximum southern extent and then began to recede northward, exposing the copperbearing trap rocks of the Upper Peninsula (Carr 2009; Ellis et al. 2011)*.

In regard to the timing of initial human mining endeavors, recent geochemical studies are consistent with the presence of substantive copper-related activities in the Lake Superior mining district as early as approximately 7000 RCYBP (8000 cal BP; Pompeani et al. 2013:5549). These miningrelated data are intriguing in regard to the origin of copper working. In order for Early Archaic groups to be involved in such industrious removal and processing of copper ore-to a magnitude extensive enough to cause conspicuous lead $(\mathrm{Pb})$ signals in lake sediments-there must have been a period of experimentation with the novel tool medium substantially prior to these mining-related dates. Unfortunately, however, the chance of finding the "first" artifact made from copper is virtually zero (Meltzer 2009; Prasciunas and Surovell 2015). In turn, this hampers our understanding of innovation processes in the North American Holocene and restricts debate on why this material was first sought and by whom.

Recent developments within Paleolithic archaeology may provide a solution. Optimal linear estimation (OLE) modeling has recently been used to reconstruct both the origin date and end date of several key Paleolithic technologies (Key, Jarić, and Roberts 2021; Key, Roberts, and Jarić 2021). Of most relevance here is Key, Roberts, and Jarić's (2021) use of OLE to estimate date of origins for the Oldowan and Acheulean. In these examples, the model inferred the first production of these technologies to be at least 36,000 and 55,000 years earlier (Oldowan and Acheulean, respectively) than the current oldest-known archaeological sites indicate. In straightforward terms, OLE models can use the oldest-known occurrences of a cultural tradition or technological phenomenon to model the length of time that it is likely to have existed prior to the current earliest-known evidence. In other words, it effectively reconstructs the portion of the archaeological record not yet discovered. In the present scenario, it would become

${ }^{*}$ This article has been amended since its original publication to correct a reference error. See doi:10.1017/aaq.2022.24. possible to estimate the duration of time that copper was worked prior to the earliest evidence of its use as a tool medium as reported by Martin (1993).

Such scenarios are not limited to the human material record, and archaeology is certainly not the only discipline confronted with reconstructing meaningful behavioral data from incomplete temporospatial datasets. Indeed, OLE has a long history. It was first developed to reconstruct the timing of species extinctions within conservation science and has since also been adopted widely within paleontological studies (Clements et al. 2013; Crees and Turvey 2014; Pimiento and Clements 2014; Roberts and Solow 2003; Solow 2005; Zhang et al. 2020). Importantly, however, OLE models have no underlying assumptions that are specific to biological organisms, and they perform equally well when predicting the origin or "extinction" of any phenomenon, as long as they are characterized by sporadic observations through time (Clements et al. 2013; Key, Roberts, and Jarić 2021; Rivadeneira et al. 2009). Here, we adopt this model and present the most accurate estimate yet for when copper tool production in North America originated.

\section{Methods}

\section{Optimal Linear Estimation}

Optimal linear estimation (OLE) modeling, as proposed by Roberts and Solow (2003), has been shown to be a robust inferential method within diverse dating scenarios (Clements et al. 2013). This includes those varying in chronological magnitude and distribution. When estimating dates of origin, OLE requires the earliest-known occurrences of a phenomenon to be entered into the model, from which it identifies the date at which the process generating the occurrence (in this case, humans producing copper artifacts) is likely to have started. As explained elsewhere (Clements et al. 2013; Key, Roberts, and Jarić 2021; Roberts and Solow 2003), OLE is based on the concept that the oldest occurrences (or most recent, if inferring extinction) entered into the model have (roughly) the same "Weibull form," irrespective of the timings of other instances later in the phenomenon's timeline. Simply, it is the 
Table 2. Optimal Linear Estimation (OLE) Modeling Results.

\begin{tabular}{llllc}
\hline & $T_{\mathrm{O}}($ Central Range Estimate) & $T_{\mathrm{O}}$ (Resampling) & $T_{\mathrm{CI}}$ (Central Range Estimate) & $T_{\mathrm{CI}}($ Resampling) \\
\hline${ }^{14} \mathrm{C}$ & 8126 & 8184 & 8914 & 9020 \\
cal BP & 9068 & 9413 & 9969 & 10,723 \\
& estimated origin & estimated origin & $95 \%$ upper bound limit & $95 \%$ upper bound
\end{tabular}

Note: Inferred origin dates for the use of copper via optimal linear estimation, using central range estimates and resampling procedures.

chronological distribution of-and intervals between-these first observations that inform the inferred date of origin, and these inferences are modeled according to defined predictions seen in Weibull distributions. To put it another way, the dated observations are used to tailor the (Weibull distribution) probability curve, from which a point of origin can be inferred. The model asks the question, Given known artifactual occurrences and past sampling effort, when would the next artifact in the sequence be expected? If no artifact has been found between this point and the current earliest occurrence, then it can be inferred that the phenomenon is unlikely to have existed prior to this point.

Full formulaic description of the OLE models are described elsewhere (Clements et al. 2013; Key, Jarić, and Roberts 2021; Solow 2005). All models were performed in $\mathrm{R}$ (version 4.0.3) using the sExtinct software package (Clements 2013). Although a fast adoption of copper use is possible, it cannot be assumed, so we did not apply the classical extinction method outlined by Solow (1993). We also used the tenth-oldest occurrence (5730 RCYBP) as the beginning of the period because there was no specific start date to the time series (Table 1).

Each OLE model produced two variables important to understanding the origin of copper production in North America. The first of these is $T_{\mathrm{O}}$ and the second is $T_{\mathrm{CI}}$. $T_{\mathrm{O}}$ represents the inferred date of origin for the use of copper within each respective model, whereas $T_{\mathrm{CI}}$ is the upper bound of each model's confidence interval. $T_{\mathrm{CI}}$ effectively details the $95 \%$ confidence limit around $T_{\mathrm{O}}$, beyond which copper only has a minimal chance of preceding it (i.e., in 95 out of 100 cases, the point or origin will be between the $T_{\mathrm{CI}}$ date and the currently earliestknown artifact). $T_{\mathrm{O}}$ represents the date at which an earlier occurrence of copper use would have been expected to have been found (relative to the current oldest) if it existed prior to his point. As stated above, $T_{\mathrm{O}}$ is defined by the temporal spacing and search intensity associated with sites used in the model, and the aforementioned Weibull distribution.

\section{Sampling Procedure}

It is generally recommended that 10 dates can be considered optimal within OLE modeling (Rivadeneira et al. 2009; Solow 2005). The inclusion of additional "younger" copper occurrences is unlikely to impact the result and could even invalidate several of the model's assumptions (Solow 2005). A detailed review of the literature was undertaken to identify the 10 oldest radiocarbon dates associated with copper use (Table 1; Figure 2). These data include radiocarbon dates gleaned from material embedded in copper tools (Beukens et al. 1992; Morris and Steinbring 2020; Pleger 2001; Pompeani et al. 2021 ${ }^{1}$; Reardon 2014), materials from cremation burials (Libby 1954), and stratigraphic material found in close association with worked copper (Martin 1993). From each site, we collected the main estimated date and date range, along with the calibrated median date and the $95.4 \%$ confidence intervals. In cases where the calibrated dates were not reported, they were calibrated to calendar ages using the IntCal20 calibration curve at $2 \sigma$ (Reimer et al. 2020) via Calib version 8.2 (Stuiver and Reimer 1993). The 10 oldest, welldocumented radiocarbon dates from archaeological contexts were used to run the analyses (Table 1). All were assumed to be discrete occurrences of the technological phenomenon (as required by the model). Within archaeological contexts, and in its most extreme interpretation, this means that each archaeological occurrence 


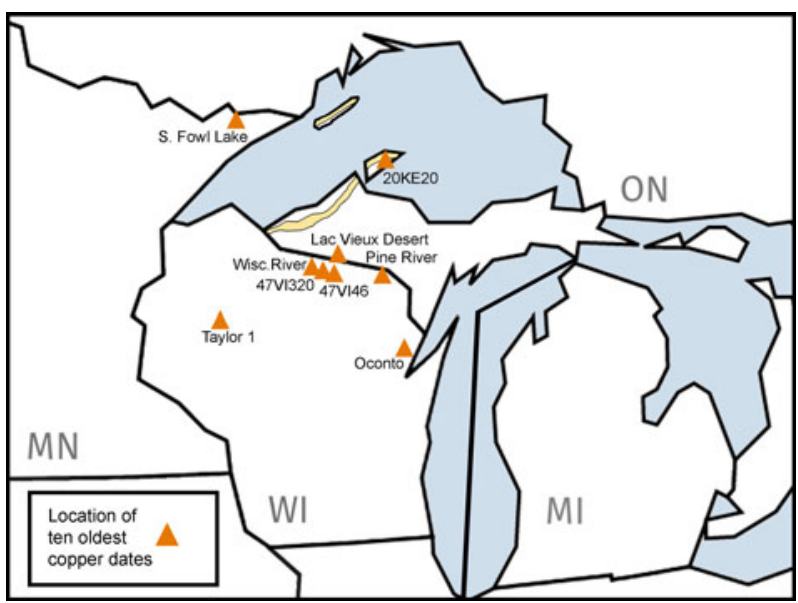

Figure 2. Map showing the location of the 10 oldest radiocarbon dates associated with copper use in the Western Great Lakes that were used in the OLE model.

is assumed to have been made by a distinct individual (i.e., a single biological repository for the cultural information required to exploit copper).

Two OLE models were initially run using the 10 main estimated dates (RCYBP) and the calibrated median dates (cal BP). In addition to this, radiocarbon dating provides potential ranges with an approximate normal distribution from the mean or calibrated median, and these enter a degree of uncertainty into any discussion of an artifact's age. To account for this, we also applied a resampling approach where a date from within each of the 10 associated date ranges was randomly drawn from a normal distribution and used instead of the main or calibrated median dates. This was repeated 10,000 times, and each randomly drawn dataset of 10 dates was assessed using the OLE method (Supplemental Table 1).

\section{Results}

All models push the origin of copper production in North America beyond 8000 RCYBP (Table 2; Figure 3). There is greater consistency between the central range estimate and resampling technique estimate within the RCYBP models relative to the cal BP estimates. Given the restricted ranges for most RCYBP data in Table 1, this is not unexpected. Indeed, OLE models using RCYBP dates infer copper production to begin $\left(T_{\mathrm{O}}\right)$ between 8126 and 8184
RCYBP. The upper bound of this date range is defined by the resampling technique, whereas the lower uses the main estimated dates. $T_{\mathrm{CI}}$ dates, beyond which copper production only has a $5 \%$ chance of preceding this point, provide a bracket of 8914-9020 RCYBP. Upper and lower bounds were again defined by the resampling technique and main estimated dates (respectively).

Calibrated dates returned estimated dates of origin $\left(T_{\mathrm{O}}\right)$ ranging between 9068 and 9413 years cal BP. The $T_{\mathrm{CI}}$ dates for these models provide upper bound limits of 9969 and 10,723 cal $\mathrm{BP}$, with the lower being derived from the median calibrated dates, and the greater resulting from the resampling technique.

\section{Future Sampling Considerations}

As described above, OLE models are generally most effective when analyzing the 10 oldest (or youngest, if inferring "extinction") dates on record. If new dates are discovered for copper artifacts, these occurrences could "replace" the more recent dates of our model (i.e., several of the artifact dates used here are less than 7000 RCYBP) and would alter the predicted date of origin inferred here. If future discoveries provide tighter date clustering around the oldest occurrences, then the inferred date of origin would likely be more recent. If future discoveries are 


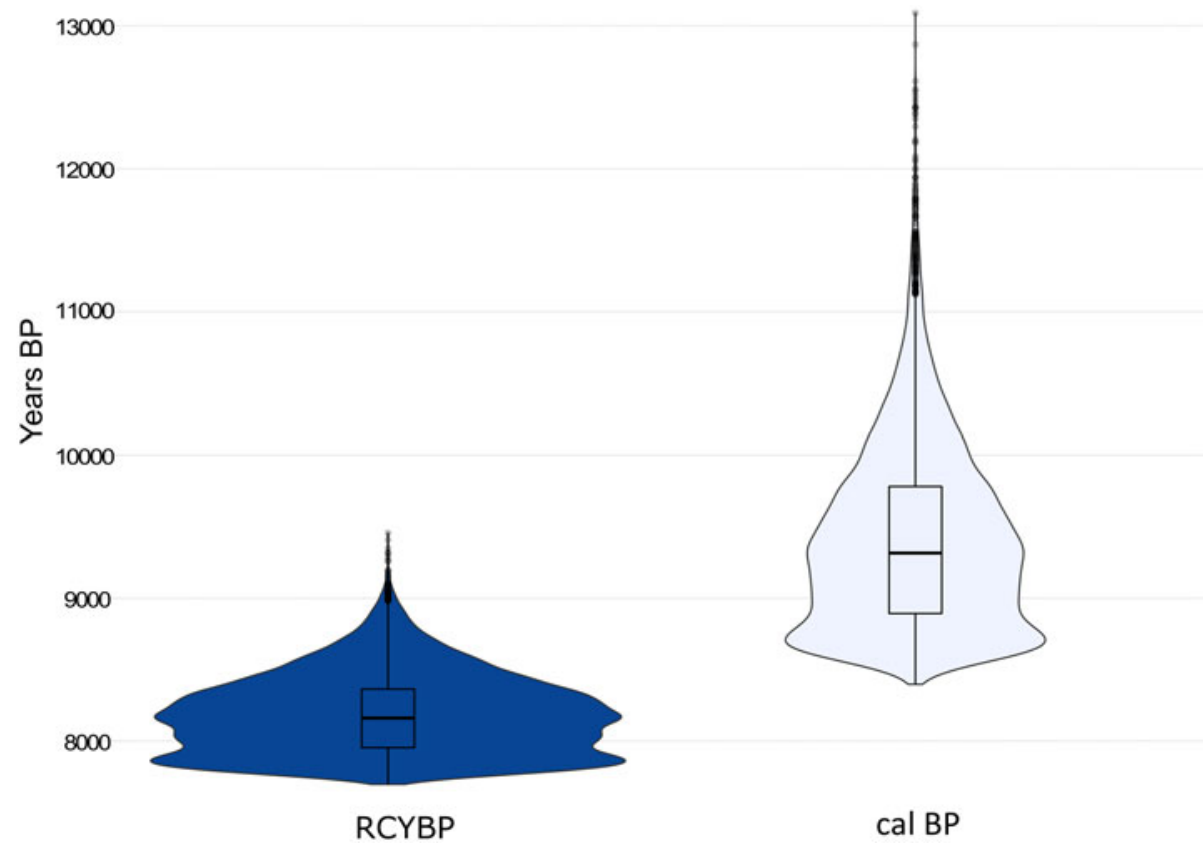

Figure 3. Violin-boxplots detailing predicted dates of origin for the use of copper by Paleoindian populations, derived from 10,000 iterations of the random sampling method.

toward the tail end of the current distribution of dates, then there would be minimal impact on the model's predictions. If future discoveries provide evidence of older copper artifacts relative to those used here, then the model would infer an older age for copper production. We would welcome future discoveries that allow additional, updated OLE models to be run. However, it is worth emphasizing that our models are robust in light of current evidence, and they provide new empirical evidence in support of previous assumptions that copper production is likely to have an earlier origin relative to current dates.

Unfortunately, the problem of finding copper artifacts that date to the Late Paleoindian time period is likely to remain challenging because the potential for finding the earliest of any cultural item is exceedingly small. Indeed, the statistical probability of finding an artifact that represents the "oldest" becomes increasingly unlikely the farther one goes back in time (Meltzer 2009; Prasciunas and Surovell 2015). This can be thought of as a simple battleship curve: the peak area represents the abundance of materials found during a cultural zenith, whereas the left tail represents the initial experimentation with a new tool medium, and the right tail represents the decline or replacement of the tool type with a new variant. This is simply because the farther the archaeological record goes back in time, the more ephemeral the record becomes (notably, this is one of the fundamental assumptions underlying OLE). This ephemerality is heightened further for pioneering populations of highly mobile hunter-gatherers. Additionally, during the initial stage of copper experimentation, there would be very few finished tools compared to the vast number of tools associated with the "Old Copper" zenith that peaked between 6000 and 3000 RCYBP. This pattern is evident in a variety of novel hunter-gatherer technologies-such as pottery-that tend to "bump along" at low frequencies (Jordan and Cummings 2014:587) until their utility is fully realized, and they eventually become a central component of a technological system.

Likewise, attempts to reconstruct the human past are further hampered by taphonomic processes and modern human interaction. This is a problem for analyzing all prehistoric materials. 
However, undersampling bias is a particular problem in this scenario given that copper tools have long been collected by hobbyists via the use of metal detectors, and therefore only a small sample of the total past assemblage is currently accessible for data analysis (Bebber and Chao 2022). Likewise, many hobbyists inadvertently destroy valuable data by "cleaning" copper specimens, which removes valuable organic material that could be used for radiocarbon dating. Additionally, it has been noted that European settlers melted and repurposed prehistoric copper tools (Brown 1904). Truly, it is difficult to comprehend the amount of early copper material that has been lost. We hope that future finds will be carefully collected, studied, and chronometrically dated. In fact, based on the results of the model used here, we should expect to eventually recover copper spearpoints with organic materials extending to $8100 \mathrm{RCYBP}$ and potentially beyond.

\section{Discussion}

The results of this study support the early Holocene use of copper by Late Paleoindian groups in North America around 8100-8200 RCYBP. The implications of these results are manifold. Here, we discuss these results in light of three questions that form the basis of archaeological inquiry: (1) when, (2) who, and (3) why, Admittedly, the questions of when and who are the more straightforward and for this reason will be discussed first. The question of why colonizing populations may have begun experimenting with a novel tool medium such as copper requires slightly more consideration and will be discussed in light of mobility, raw material availability, and huntergatherer innovation.

\section{When}

The timing of the initial occupation in the Upper Peninsula is largely dependent on climatological conditions and glacial activity. Indeed, when investigating the colonization of the western Great Lakes region, the position of the Laurentide Ice Sheet and the fluctuation of its southern border are key considerations (Figure 4a). By the onset of the Younger Dryas (ca. 11,000 RCYBP; Eren 2012), the Laurentide Ice Sheet had begun its retreat northward into the Lake Superior basin. However, due to the cooling associated with the Younger Dryas event, there was a readvance of glacial ice that began around 10,400 RCYBP and reached its maximum southern extent by 10,025 RCYBP (Lowell et al. 1999; Pregitzer et al. 2000). The Marquette readvance covered most of the Upper Peninsula of Michigan for approximately 360-700 years (Derouin et al. 2007), after which it once again began its northward retreat between 9700 and 9500 RCYBP (Hill 2012). It is likely that the northward ice retreat in the Upper Peninsula began along the western glacial border and then moved eastward over the course of a few hundred years. This process would have allowed for reoccupation of northeastern Wisconsin prior to the initial eastward colonization of Michigan's Upper Peninsula (Derouin et al. 2007).

The final glacial retreat, and the subsequent opening of the landscape for reoccupation, occurred during the Late Paleoindian ${ }^{2}$ period. This period in the copper mining area is not precisely dated due to a lack of chronometric dates associated with diagnostic materials. Most of the cultural dates are estimates based on lithic assemblages containing diagnostic point types from the Late Paleoindian "Plano" phase (Clark 1989). This phase is not well defined for the Lake Superior region, but it generally includes materials similar to those of the Agate Basin complex or Cody complex, which are both based on Paleoindian cultural materials in western North America. Agate Basin points date between 10,500 and 10,000 RCYBP (Eren et al. 2022; Holliday 2000). The Cody complex dates to 10,100-8000 RCYBP and contains both Scottsbluff- and Eden-style projectile points (Knell and Muñiz 2013). Consequently, there is close temporal proximity between these dates and the predicted origin of copper use at 8100 RCYBP.

\section{Who}

It is clear that prior to the Younger Dryas (ca. 11,000 RCYBP), early Paleoindian groups were inhabiting southern and central Wisconsin. An abundance of "Clovis-like" sites (Ellis et al. 2011) show that early Paleoindian groups had migrated into modern-day Wisconsin by 11,000 RCYBP. There are a multitude of finds from 

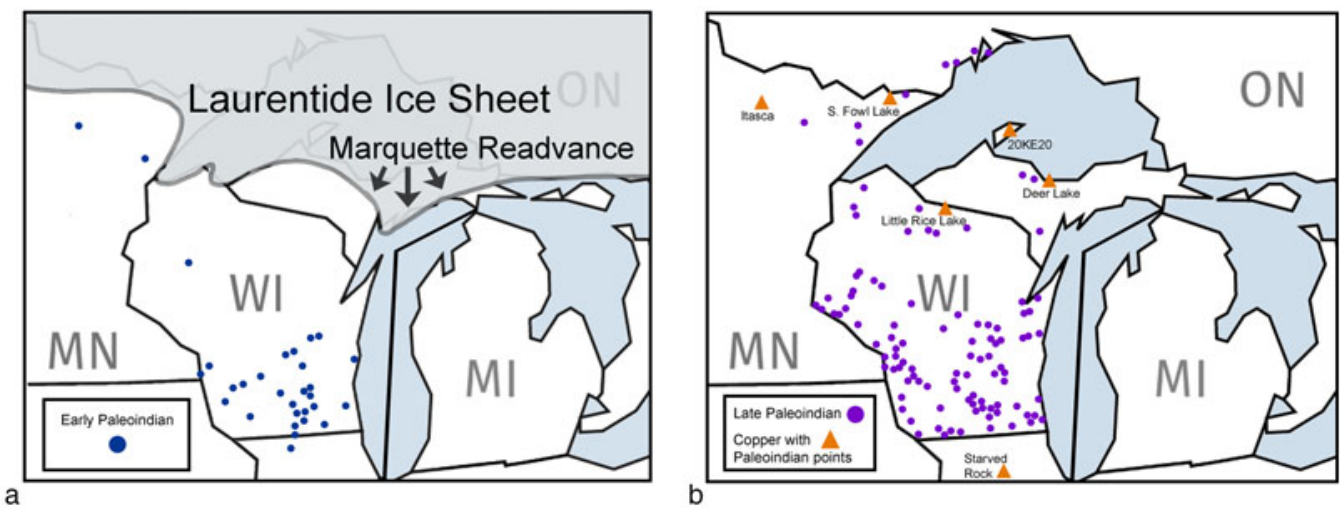

Figure 4. Habitation patterns of Western Great Lakes: (a) Early Paleoindian site distribution (based on Ellis et al. 2011; Mulholland et al. 1998) showing approximate maximum extent of the Marquette Readvance ca. 10,025 RCYBP; (b) Late Paleoindian site distribution after glacial retreat (after 9500 RCYBP), along with sites where copper materials were found with Late Paleoindian cultural materials (McCreary site, Manitoba, not shown on map). (Color online)

this time period in southern and central parts of the state, and a few sites in the northwestern areas (Amick et al. 1999; Loebel 2005). However, there are currently no Clovis-like sites either in the northeastern portion of Wisconsin or in the Upper Peninsula of Michigan that show evidence for occupation during Early Paleoindian times (Ellis et al. 2011). Indeed, distribution data suggest that the Younger Dryas cooling event (ca. 11,000-10,000 RCYBP; Eren 2012) had a dramatic effect on Paleoindian landscape use in northern regions. During the Marquette readvance, Paleoindian site distribution suggests a severe southern retraction when compared to earlier Clovis-like site distributions. During the Younger Dryas, there are almost no Folsom-like sites in Wisconsin, and the few that have been recorded occur in a range much farther south (Figure 4a) than in the preceding era (Ellis et al. 2011). For the most part, it appears that during the Marquette readvance, the northern part of Wisconsin was abandoned. However, shortly after 10,000 RCYBP, the southern lobe of the Laurentide Ice Sheet began to recede, and with this recession came the repopulation of northern Wisconsin and the initial colonization of the Upper Peninsula. This initial colonization took place during a warming period that occurred during the transition between the late Pleistocene and early Holocene (Derouin et al. 2007). Due to the warming oscillations, Paleoindian populations may have been drawn northward as the climate improved and new landscapes became available.

The first Late Paleoindian cultural material in Michigan's Upper Peninsula is closely related to Agate Basin, which is generally associated with Late Paleoindian "Plano" groups from the northern Great Plains and dates to the period of 10,500-10,000 RCYBP (Eren et al. 2022; Hofman and Graham 1998). The Agate Basin points found in northern Michigan are generally intact specimens made from exotic lithic raw materials, most often Hixton silicified sandstone, which is the most common raw material used by western Great Lakes Late Paleoindian groups (Carr and Boszhardt 2010). Clark (1989) notes that formal tools such as projectile points are made of Hixton silicified sandstone, with little resharpening or debitage, whereas more expedient tools were made on local quartzites and are associated with significant tool production waste. Overall, the lithic data suggests the presence of highly mobile groups engaged in long-distance logistical mobility from known toolstone quarries to the south, such as Silver Mound in Wisconsin (Carr 2009; Clark 1989; Ellis et al. 2011).

Of central interest here are the few sites in the Upper Peninsula that contain Paleoindian lithic materials associated with copper materials (Figure 4b). Buckmaster and Paquette (1988) and Clark (1989) analyzed Late Paleoindian artifact clusters that occurred in Marquette County, Michigan. Theses clusters were distributed 
around Deer Lake, situated $20 \mathrm{~km}$ south of the modern Lake Superior shoreline. In some instances, copper materials were found with Late Paleoindian-style tools made on Hixton silicified sandstone sourced from Silver Mound Wisconsin (Martin 1999). The Deer Lake artifact clusters contained points consistent with Plano cultural materials, and a few clusters contained Paleoindian Eden-Scottsbluff-style points, which span a time period of approximately 10,100 8100 RCYBP (Knell and Muñiz 2013).

Farther to the west of the mining region, copper materials have been found in association with Late Paleoindian projectile points in the South Fowl Lake area of Minnesota (Harrison et al. 1995). At several sites in this area, copper material was found along with Plano projectile points manufactured on Hixton silicified sandstone. And, although no direct dates are associated with the copper materials, Dawson (1983) provides an occupation date for the South Fowl Lake area of $8480 \pm 390$ RCYBP, generated by radiocarbon dating of an early cremation burial. However, the relationships between the cultural materials remain equivocal.

Taken together, these data show that beginning in the Late Paleoindian era, the earliest inhabitants of Michigan's mining district-and neighboring regions-were highly mobile groups that valued quality raw materials for projectile-point production. These data inform our discussion of why Paleoindian groups may have innovated copper tools.

\section{Why}

Identifying precisely why pioneering populations experiment with novel tool media is a multifaceted endeavor. There are undoubtedly a variety of interrelated factors that may stimulate experimentation as groups encounter unknown environments-environments that present new possibilities in terms of subsistence and technology. Here, the incipient experimentation of metal as tool material will be considered in light of Late Paleoindian mobility patterns, regional raw material availability and quality, and huntergatherer innovation.

Late Paleoindian Mobility, Use of Materials, and Necessity of Quality Tool Media. As discussed above, evidence from Late Paleoindian assemblages shows that groups were highly mobile and continued to import high-quality lithic raw materials from over $200 \mathrm{~km}$ away in the western Great Lakes region, which is a contrasting pattern to Late Paleoindian trends found in the eastern Great Lakes (Ellis et al. 2011). This pattern sheds lights on a key factor -lack of toolstone-that may have driven interest in novel tool materials such as copper in the Lake Superior region. Overall, there is a relative dearth of chert outcrops and a general lack of quality toolstone compared to areas to the south and east. In northern Michigan, the most readily available lithic raw materials are quartzites, rhyolites, and quartz (Hill 2012). A limited amount of chert, in the form of small nodules, could have been sourced from glacially deposited tills. Of interest is that "float" copper can also be found in these glacial tills (Martin 1999). Consequently, it is quite possible that the early colonizers of the region first encountered the novel material while looking for adequate toolstone.

Indeed, quality tool material would have been a highly valued commodity, especially for the manufacture of formal tools. In fact, studies have argued that local toolstones were regularly heat treated to improve their production-related characteristics (Behm and Faulkner 1974; Mraz et al. 2019; Purdy and Brooks 1971). One could imagine that copper nuggets might have found their way into the heat treatment process (Pargeter and Schmidt 2020). If so, Late Paleoindian tool manufacturers would have had the opportunity to observe the unique properties displayed by copper when heated. It is likely that Late Paleoindian groups first encountered float copper in the glacial drift area far south of the mining districts of Lake Superior. Steinbring (1991) suggests that this novel material was quickly adopted as a tool medium by Plano groups, possibly as an adaptation to hunting in the newly expanded northern prairie.

From a technological perspective, studies have repeatedly shown that in comparison to later groups, Paleoindians designed their spearpoints to be durable (Buchanan and Hamilton 2020). It can therefore be inferred that copper would be an ideal medium for making large, durable, field-adapted, hunting weaponry. In the northern Great Plains, subsistence was largely 
geared toward the taking of large herd animals, primarily bison (Bamforth 2011; Buchanan et al. 2011; Carlson and Bement 2013; Speth 2020). In this regard, it is worth noting that a few sites to the west of the copper heartland demonstrate the co-occurrence of copper materials and bison remains. These include the Itasca site in Minnesota (Shay 1971), and the Jansson site in Manitoba (Steinbring 1970).

Admittedly, it is uncertain precisely how early copper tools would have functioned as adaptive modifications to an already successful technological system, or what advantage (if any) they may have offered plains hunters. Indeed, experimental research has demonstrated that there is no significant difference in penetration depth between projectile points made from copper and those made from stone (Bebber 2021; Bebber and Eren 2018). Therefore, it is likely that other factors-such as the increased durability of copper tools (Bebber et al. 2019) or, alternatively, the limited availability of lithic raw materials (Hill 2012) — were driving the interest in copper projectile points.

Late Paleoindian Innovation. Based on an analysis of various copper materials found in Manitoba, Steinbring (1970:55) defined copper McCreary points as "a generalized flint Agate Basin, hammered from native copper." $\mathrm{He}$ asserts that McCreary points date to as early as 8500 RCYBP in western Manitoba, but that the technology would have had to evolved prior to their early appearance in the west. This means that Late Paleoindian groups would have begun experimenting with float copper in southern glacial drift regions possibly as early as 10,200 RCYBP, when Agate Basin materials first appear in the western Great Lakes (Ellis et al. 2011). In fact, support for this scenario is found at the Starved Rock site in northern Illinois (Mayer-Oakes 1951), which is situated in the range of float copper dispersal (Bornhorst 2017; Bornhorst and Lankton 2009). Here, a copper lanceolate point was found in the lowest stratigraphic levels along with late Paleoindian-style points (MayerOakes 1951). Consequently, it is possible that as groups moved farther northward, into areas with lower-quality toolstone, demand for copper as a tool medium intensified to the point where surface-sourced copper materials were no longer sufficient. Such a scenario may have stimulated the first attempts at copper extraction from the trap rock of the Upper Peninsula. Of interest to this latter possibility is mining-related data gleaned from lake sediments. Geochemical studies have revealed signatures in Copper Falls Lake and Lake Manganese that suggest that copper mining and processing began in the Upper Peninsula as early as approximately 7000 RCYBP (Pompeani et al. 2013). This suggests that copper usage had accelerated to a magnitude warranting the increased energy expenditure associated with copper mining (Bastian 1963; Bebber 2021; Trotter 2017) by the transition from Late Paleoindian to Early Archaic period in the Lake Superior region.

Hunter-Gatherer Innovation. Moving beyond the more rudimentary questions of temporospatial origins, the results here can inform our understanding of hunter-gatherer innovation during the initial colonization of the western Great Lakes region. Innovation is a central topic in the study of past culture because it is a vital source of artifactual variability and complexity. Indeed, investigating how and why innovation occurs is key to understanding cultural evolution and our human ability to adapt to novel situations or fluctuating environments.

Regarding hunter-gatherer innovation, Hewlett (2016:10) states that "the vast majority of innovations are not entirely new; they are novel recombinations or small additions to existing beliefs, practices, technology, institutions, etc." Indeed, this is apparent in the morphological similarities of the earliest copper tool forms and Late Paleoindian lanceolate forms. However, here, the manipulation of native copper represents more than a "small addition" to an existing practice: it represents a dramatic shift in the manufacturing procedure. Principally, the innovation of copper as a tool medium required a sudden switch from a purely reductive tool production process to one that can be conceptualized as an additive-reductive tool production process (Schillinger et al. 2014). The innovation of a completely novel production procedure involving the hammering of a copper nugget into a large, lanceolate point form, represents an unprecedented technological shift-one so extraordinary that it cannot be fully expressed 
here but warrants careful future consideration. As it stands, the copper tool production of the western Great Lakes predates all known utilitarian uses of metal technologies in the world. Of interest is that although hammered native copper has been found in the form of small decorative items such as beads and pins, as early as 10,000 RCYBP in Anatolia (Özdoğan and Özdoğan 1999; Yalçin 2017), copper was not used for producing tools (i.e., projectiles or knives) until after the development of extractive metallurgy and casting technologies, which occurred sometime after 7000 RCYBP (Yalçin 2017). Consequently, North America's copper technology represents the earliest use of metal forging techniques to produce projectiles, knives, axes, and other functional tools.

The results presented here shed light on the behavior of pioneering populations as they enter terra incognita. As observed by Hiscock and colleagues (2016:9), "The timing of these innovations at the point of colonization suggests that dispersing humans were often innovating as they entered new territories." Indeed, this process of imaginative experimentation and the rapid development of a complex new production technique are evident in the patterns discussed herein. This pattern of innovation evident in Paleoindian lifeways would have facilitated changes to mobility and production systems that best suit the raw materials available in a given locale. This flexibility allowed for groups to expand into an area with generally lower availability of toolstone. In doing so, these pioneering Paleoindian groups initiated localized practices that would ultimately manifest fully as the defining characteristics of Archaic traditions. These developing social practices are evinced by cremation rituals (Buckmaster and Paquette 1988) and could signal use of copper as a trade item or social signal (Pleger 2001; Pleger and Stoltman 2009). By adapting a key component of their technological system, these early groups established novel economic systems focused on the extraction and production of copper materials. In fact, it is possible that the new tool medium and production efforts generated social and trade networks that would ultimately culminate in the Late Archaic and Early Woodland cultural practices evinced by classic Old Copper
Culture sites such as Oconto (Ritzenthaler and Wittry 1952), Osceola (Ritzenthaler 1957; Wittry and Ritzenthaler 1956; 1957), and Reigh (Baerreis et al. 1954; Ritzenthaler et al. 1957).

\section{Conclusion}

The OLE results presented here suggest that the invention of copper as a tool medium occurred shortly after the first pioneering populations encountered the novel material during the Pleistocene-Holocene transition. The proposed origin dates projected here (ca. 8100 RCYBP) reveal several important features about the behavior of pioneering populations. First, the invention of copper as a tool medium exemplifies the importance of novelty during the initial colonization of North America. As humans moved into a newly exposed landscape, their technological systems were adapted and transformed via the exploration of an entirely new tool medium. Second, the early invention of copper as a tool medium in the western Great Lakes regions antedates all other metallurgical developments in the world. This phenomenon represents the earliest use of metal for utilitarian copper tool production. Third, the processes that began in the western Great Lakes nearly 10,000 years ago represent the onset of regional differentiation in technological, economic, and social traditions during the earliest period of exploration and settlement. These early developments formed the basis for patterns evident in later Archaic period groups, whose origins, we argue, are located within Paleoindian adaptive behaviors.

Overall, this analysis adds a unique perspective to our understanding of Late Paleoindian technological innovation in the context of the colonizing process. These patterns suggest a high level of adaptability and creativity, along with a dynamic, continually evolving, technical skill set. And although there is still much unknown about Paleoindian social life and artistic expression, we argue that by investigating the first human interaction with metal, we can provide a richer narrative of Paleoindian lifeways. Indeed, further studies will, ideally, elucidate the magnitude and structure of technological experimentation and adaptation as revealed by pioneering populations such as those in the western Great Lakes. 
Acknowledgments. Bebber is financially supported by the Kent State University College of Arts and Sciences and gratefully acknowledges the support received from the Robert J. and Lauren R. Patten Endowment. Key's research is supported by the Royal Society. We are both grateful to D. Roberts and I. Jaric for their advice concerning the OLE models.

Data Availability Statement. Original data were presented in this article through the OLE resampling procedure and are available in the online supplemental materials.

Supplemental Material. For supplemental material accompanying this article, visit https://doi.org/10.1017/aaq.2021. 121.

Supplemental Table 1. OLE Copper Resampling Data.

\section{Notes}

1. It has been cited in multiple locations (e.g., Pompeani et al. [2021] and also on the Milwaukee Public Museum website) that Binford (1962) provides a primary source of reference for the date of 7560 RCYBP. Lab numbers are not reported along with this radiocarbon date, and the precise origin for this reference is unknown. Binford (1962) does not provide results of radiocarbon dates that he himself generated. Instead, he is discussing the then ongoing debate about the accuracy of the cremation dates from Oconto (Mason and Mason 1961). We note that more recent radiocarbon dating of the materials in question from the Oconto site (Pleger $2001)$ support the early dates $(7510 \pm 600)$ originally provided by Libby (1954:740).

2. Throughout this manuscript, we chose to use the term "Late Paleoindian" because it represents the earliest cultural materials associated with worked copper in multiple instances. Overall, the delineation of the Paleoindian-Archaic transition is poorly understood for the Lake Superior region, as is the case for various areas of the Upper Great Lakes. As discussed by Kuehn (2002), there is a relative paucity of radiocarbon dates available for this region, and chronologies remain incomplete. There is also overlap of Late Paleoindian and Early Archaic materials in most locales, which further adds to the confusion about the cultural trajectory during this transitory period in human lifeways.

\section{References Cited}

Amick, Daniel, Robert F. Bozhardt, Kenneth Hensel, Matthew Glenn Hill, Thomas J. Loebel, and Dean Wilder

1999 Pure Paleo in Western Wisconsin. Report of Investigations No. 350. Mississippi Valley Archaeology Center at the University of Wisconsin, LaCrosse.

Baerreis, David A., Hiroshi Daifuku, and James E. Lunstad 1954 The Burial Complex of the Reigh Site, Winnebago County, Wisconsin. Wisconsin Archeologist 35(1):1-36.

Bamforth, Douglas B.

2011 Origin Stories, Archaeological Evidence, and Postclovis Paleoindian Bison Hunting on the Great Plains. American Antiquity 76:24-40.

Bastian, Tyler J.

1963 Prehistoric Copper Mining in Isle Royale National Park, Michigan. PhD dissertation, Department of Anthropology, University of Utah, Salt Lake City.
Bebber, Michelle R.

2021 The Role of Functional Efficiency in the Decline of North America's Copper Culture (8000-3000 BP): An Experimental, Ecological, and Evolutionary Approach. Journal of Archaeological Method and Theory 28:1224-1260. DOI:10.1007/s10816-020-09497-0.

Bebber, Michelle R., and Anne Chao

2022 The Diversity of North America's "Old Copper" Projectile Points. In Defining and Measuring Diversity in Archaeology, edited by Briggs Buchanan and Metin Eren, pp. 1-16. Berghahn, New York.

Bebber, Michelle R., and Metin I. Eren

2018 Toward a Functional Understanding of the North American Old Copper Culture "Technomic Devolution." Journal of Archaeological Science 98:34-44.

Bebber, Michelle R., Alastair J. M. Key, Michael Fisch, Richard S. Meindl, and Metin I. Eren

2019 The Exceptional Abandonment of Metal Tools by North American Hunter-Gatherers, 3000 BP. Scientific Reports 9(1):1-4.

Behm, Jeffery A., and Alaric Faulkner

1974 Hixton Quartzite: Experiments in Heat Treatment. Wisconsin Archeologist 55(4):271-276.

Beukens, Roelf P., Larry A. Pavlish, Ronald G. V. Hancock, Ronald M. Farquhar, Graham C. Wilson, Patrick J. Julig, and William Ross

1992 Radiocarbon Dating of Copper-Preserved Organics. Radiocarbon 34:890-897.

Binford, Lewis R.

1962 Radiometric Analysis of Bone Material from the Oconto Site. Wisconsin Archeologist 43(2):31-41.

Bornhorst, Theodore J.

2017 Float Copper, Keweenaw Peninsula, Michigan. A. E. Seaman Mineral Museum, Web Publication 3. Electronic document, https://museum.mtu.edu/sites/default/ files/2020-12/AESMM_Web_Pub_3_Float_Copper_ Michigan_2017.pdf, accessed November 29, 2021.

Bornhorst, Theodore J., and Larry D. Lankton

2009 Copper Mining: A Billion Years of Geologic and Human History. In Michigan Geography and Geology, edited by Randall J. Schaetzl, Joe T. Darden, and Danita S. Brandt, pp. 150-173. Pearson Custom Publishing, New York.

Brown, Charles E.

1904 The Native Copper Implements of Wisconsin. Wisconsin Archeologist 3(2):49-93.

Buchanan, Briggs, Mark Collard, Marcus J. Hamilton, and Michael J. O'Brien

2011 Points and Prey: A Quantitative Test of the Hypothesis That Prey Size Influences Early Paleoindian Projectile Point Form. Journal of Archaeological Science 38:852-864.

Buchanan, Briggs, and Marcus J. Hamilton

2020 Scaling Laws of Paleoindian Projectile Point Design. Journal of Archaeological Method and Theory 28:580-602.

Buckmaster, Marla M., and James Paquette

1988 The Gorto Site: Preliminary Report on a Late PaleoIndian Site in Marquette County, Michigan. Wisconsin Archeologist 69(3):101-124.

Burger, Richard L., and Robert B. Gordon

1998 Early Central Andean Metalworking from Mina Perdida, Peru. Science 282:1108-1111.

Carlson, Kristen, and Leland Bement

2013 Organization of Bison Hunting at the Pleistocene/ Holocene Transition on the Plains of North America. Quaternary International 297:93-99. 
Carr, Dillon H.

2009 From Silver Lake to Deer Lake: Variability in the Early Holocene Human Occupation of Michigan's Upper Peninsula. Wisconsin Archeologist 90(1-2):31-46.

Carr, Dillon H., and Robert F. Boszhardt

2010 Silver Mound, Wisconsin: Source of Hixton Silicified Sandstone. Midcontinental Journal of Archaeology 35:5-36.

Clark, Caven P.

1989 Plano Traditional Lithics from the Upper Peninsula of Michigan. Midwest Archaeologist 35:88-112.

1991 Group Composition and the Role of Unique Raw Materials in the Terminal Woodland Substage of the Lake Superior Basin. PhD dissertation, Department of Anthropology, Michigan State University, East Lansing.

Clements, Christopher F.

2013 sExtinct R Package. Electronic document, https:// cran.rproject.org/src/contrib/Archive/sExtinct/ accessed July 16, 2020.

Clements, Christopher F., Nicholas T. Worsfold, Philip H. Warren, Ben Collen, Nick Clark, Tim M. Blackburn, and Owen L. Petchey

2013 Experimentally Testing the Accuracy of an Extinction Estimator: Solow's Optimal Linear Estimation Model. Journal of Animal Ecology 82:345-354.

Crees, Jennifer J., and Samuel T. Turvey

2014 Holocene Extinction Dynamics of Equus hydruntinus, a Later-Surviving European Megafaunal Mammal. Quaternary Science Reviews 91:16-29.

Dawson, Kenneth C. A

1983 Cummins Site: A Late Paleo-Indian (Plano) Site at Thunder Bay, Ontario. Ontario Archaeology 39: 3-31.

Derouin, Sarah A., Thomas V. Lowell, and Irka Hajdas

2007 Landscape Evolution and Deglaciation of the Upper Peninsula, Michigan: An Examination of Chronology and Stratigraphy in Kettle Lake Cores. Journal of Great Lakes Research 33:875-886.

Ehrhardt, Kathleen L.

2009 Copper Working Technologies, Contexts of Use, and Social Complexity in the Eastern Woodlands of Native North America. Journal of World Prehistory 22:213-235.

Ellis, Christopher J., Dylan H. Carr, and Thomas J. Loebel

2011 The Younger Dryas and Late Pleistocene Peoples of the Great Lakes region. Quaternary International 242:534 545.

Eren, Metin I. (editor)

2012 Hunter-Gatherer Behavior: Human Response during the Younger Dryas. Left Coast Press, Walnut Creek, California.

Eren, Metin I., Michelle R. Bebber, Edward J. Knell, Brett Story, and Briggs Buchanan

2022 Plains Paleoindian Projectile Point Penetration Potential. Journal of Archaeological Research, in press.

Eren, Metin I., David J. Meltzer, and Brian N. Andrews

2018 Is Clovis Technology Unique to Clovis? PaleoAmerica 4:202-218.

Gibbon, Guy

1998 Old Copper in Minnesota: A Review. Plains Anthropologist 43:27-50.

Groucutt, Huw S.

2020 Culture and Convergence: The Curious Case of the Nubian Complex. In Culture History and Convergent Evolution, edited by Christopher W. Carleton, pp. 5586. Springer, Cham, Switzerland.
Harrison, Christina, Elaine Redepenning, Christopher I. Hill, George (Rip) Rapp Jr., Stanley Aschenbrenner, James K. Huber, and Susan C. Mulholland

1995 The Paleo-Indian of Southern St. Louis County, Minnesota: The Reservoir Lakes Complex. University of Minnesota Interdisciplinary Archaeological Studies No. 4. Kendall/Hunt Publishing Company, Dubuque, Iowa. Hewlett, Barry S.

2016 Social Learning and Innovation in Hunter-Gatherers. In Social Learning and Innovation in Contemporary Hunter-Gatherers, edited by Hideaki Terashima and Barry S. Hewlett, pp. 1-15. Springer, Tokyo.

Hill, Mark Andrew

2006 The Duck Lake Site and Implications for Late Archaic Copper Procurement and Production in the Southern Lake Superior Basin. Midcontinental Journal of Archaeology 31:213-247.

2012 The Benefit of the Gift: Social Organization and Expanding Networks of Interaction in the Western Great Lakes Archaic. Berghahn Books, New York.

Hiscock, Peter, Sue O'Connor, Jane Balme, and Tim Maloney

2016 World's Earliest Ground-Edge Axe Production Coincides with Human Colonisation of Australia. Australian Archaeology 82:2-11.

Hofman, Jack L., and Russell W. Graham

1998 The Paleo-Indian Cultures of the Great Plains. In Archaeology of the Great Plains, edited by Raymond Wood, pp. 87-139. University Press of Kansas, Lawrence.

Holliday, Vance T.

2000 The Evolution of Paleoindian Geochronology and Typology on the Great Plains. Geoarchaeology 15:227-290.

Hunzicker, David A.

2002 Little Rice Lake Site (47V1272): An Old Copper Complex Manufacturing Site in Vilas County, WI. Wisconsin Archeologist 83(1):45-62.

Jordan, Peter, and Vicki Cummings

2014 Prehistoric Hunter-Gatherer Innovations. In The Oxford Handbook of the Archaeology and Anthropology of Hunter-Gatherers, edited by Vicki Cummings, Peter Jordan, and Marek Zvelebil, pp. 585-606. Oxford University Press, Oxford.

Key, Alastair J. M., Ivan Jarić, and David L. Roberts

2021 Modelling the End of the Acheulean at Global and Continental Levels Suggests Widespread Persistence into the Middle Palaeolithic. Humanities and Social Sciences Communications 8:55.

Key, Alastair J. M., David L. Roberts, and Ivan Jarić

2021 Statistical Inference of Earlier Origins for the First Flaked Stone Technology. Journal of Human Evolution 154:102976. DOI: 10.1016/j.jhevol.2021.102976.

Knell, Edward J., and Mark P. Muñiz

2013 Introducing the Cody Complex. In Paleoindian Lifeways of the Cody Complex, edited by Edward J. Knell and Mark P. Muñiz, pp. 3-28. University of Utah Press, Salt Lake City.

Kuehn, Steven R.

2002 Defining the Temporal Boundaries of the Middle Archaic: Old and New Evidence from Southern Wisconsin. Wisconsin Archeologist 83(1):19-44.

Libby, Willard F.

1954 Chicago Radiocarbon Dates V. Science 120:733-742. Loebel, Thomas J.

2005 The Organization of Early Paleoindian Economies 
in the Western Great Lakes. PhD dissertation, Department of Anthropology, University of Illinois, Chicago.

Lowell, Thomas V., Graham J. Larson, John D. Hughes, and George H. Denton

1999 Age Verification of the Lake Gribben Forest Bed and the Younger Dryas Advance of the Laurentide Ice Sheet. Canadian Journal of Earth Sciences 36:383-393.

Maguire, Leanna, Briggs Buchanan, Matthew T. Boulanger, Brian G. Redmond, and Metin I. Eren

2018 On the Late Paleoindian Temporal Assignment for the Honey Run Site (33-Co-3), Coshocton County, Ohio: A Morphometric Assessment of Flaked Stone Stemmed Lanceolate Projectile Points. Journal of Archaeological Science: Reports 20:588-595.

Martin, Susan R.

1999 Wonderful Power: The Story of Ancient Copper Working in the Lake Superior Basin. Wayne State University Press, Detroit.

Martin, Susan R. (editor)

1993 20KE20: Excavations at a Prehistoric Copper Workshop. Michigan Archaeologist 39(3-4):127-193.

Mason, Carol I., and Ronald J. Mason

1961 The Age of Old Copper. Wisconsin Archeologist 42 (4):143-155.

Mayer-Oakes, William J.

1951 Starved Rock Archaic: A Prepottery Horizon from Northern Illinois. American Antiquity 16:313-324.

Meltzer, David J.

2009 First Peoples in a New World: Colonizing Ice Age America. University of California Press, Berkeley.

Morris, Gordon K., and Jack Steinbring

2020 Radiocarbon Dates for Old Copper in Rusk County, Wisconsin. Central States Archaeological Journal 67:20-22.

Mraz, Veronica, Mike Fisch, Metin I. Eren, C. Owen Lovejoy, and Briggs Buchanan

2019 Thermal Engineering of Stone Increased Prehistoric Toolmaking Skill. Scientific Reports 9(1):1-8.

Mulholland, Susan C., Stephen L. Mulholland, Gordon R. Peters, James K. Huber, and Howard D. Mooers

1998 Paleo-Indian Occupations in Northeastern Minnesota: How Early? North American Archaeologist 18:371-400.

Norris, James D., Charles Stephens, and Metin I. Eren

2019 Early-and Middle-Stage Fluted Stone Tool Bases Found near Fox Lake, Wayne County Ohio: Clovis or Not? Journal of Archaeological Science: Reports 25:1-6.

O'Brien, Michael J., Briggs Buchanan, and Metin I. Eren (editors)

2018 Convergent Evolution in Stone-Tool Technology. MIT Press, Cambridge, Massachusetts.

Özdoğan, Mehmet, and Aslı Özdoğan

1999 Archaeological Evidence on the Early Metallurgy at Çayönü Tepesi. In The Beginnings of Metallurgy: Proceedings of the International Conference "The Beginnings of Metallurgy," edited by Andreas Hauptmann, E. Pernicka, T. Rehren, and Ü. Yalçin, pp. 13-22. Der Anschnitt Beiheft 4. Deutsches Bergbau-Museum, Bochum, Germany.

Pargeter, Justin, and Patrick Schmidt

2020 "Simple" Surface-Fire Heat Treatment Significantly Improves Silcrete Flake Quality and Flaking Efficiency. Journal of Archaeological Science: Reports 30:102203. DOI:10.1016/j.jasrep.2020.102203.

Patterson, Clair C.

1971 Native Copper, Silver, and Gold Accessible to Early Metallurgists. American Antiquity 36:286-321.
Pettipas, Leo.

1985 Recent Developments in Paleo-Indian Archaeology in Manitoba. In Contributions to Plains Prehistory: The 1984 Victoria Symposium, Archaeological Survey of Alberta Occasional Paper No. 26, edited by David V. Burley, pp. 39-63. Alberta Culture Historical Resources Division, Edmonton.

Pimiento, Catalina, and Christopher F. Clements

2014 When Did Carcharocles Megalodon Become Extinct? A New Analysis of the Fossil Record. PLoS ONE 9(10):e0117877. DOI:10.1371/journal.pone. 0117877.

Pleger, Thomas C.

2001 New Dates for the Oconto Old Copper Culture Cemetery. Wisconsin Archeologist 82(1-2):87-100.

Pleger, Thomas C., and James B. Stoltman

2009 The Archaic Tradition in Wisconsin. In Archaic Societies: Diversity and Complexity across the Midcontinent, edited by Thomas E. Emerson, Dale L. McElrath, and Andrew C. Fortier, pp. 697-724. SUNY Press, Albany, New York.

Pompeani, David P., Mark B. Abbott, Byron A. Steinman, and Daniel J. Bain

2013 Lake Sediments Record Prehistoric Lead Pollution Related to Early Copper Production in North America. Environmental Science \& Technology 47:5545-5552.

Pompeani, David P., Byron A. Steinman, Mark B. Abbott, Katherine M. Pompeani, William Reardon, Seth DePasqual, and Robin H. Mueller

2021 On the Timing of the Old Copper Complex in North America: A Comparison of Radiocarbon Dates from Different Archeological Contexts. Radiocarbon 63:1-19.

Prasciunas, Mary M., and Todd A. Surovell

2015 Reevaluating the Duration of Clovis: The Problem of Non-Representative Radiocarbon. In Clovis: On the Edge of a New Understanding, edited by Ashley M. Smallwood and Thomas A. Jennings, pp. 21-35. Texas A\&M University Press, College Station.

Pregitzer, Kurt S., David D. Reed, Theodore J. Bornhorst, David R. Foster, Glenn D. Mroz, Jason S. McLachlan, Peter E. Laks, Douglas D. Stokke, Patrick E. Martin, and Shannon E. Brown

2000 A Buried Spruce Forest Provides Evidence at the Stand and Landscape Scale for the Effects of Environment on Vegetation at the Pleistocene/Holocene Boundary. Journal of Ecology 88:45-53.

Purdy, Barbara A., and H. K. Brooks

1971 Thermal Alteration of Silica Minerals: An Archeological Approach. Science 173:322-325.

Reardon, Bill

2014 Oldest Carbon-14 Dated Copper Projectile Points from Wisconsin. Wisconsin Archeologist 95(1):86-87.

Reimer, Paula J., William E. N. Austin, Edouard Bard, Alex Bayliss, Paul G. Blackwell, Christopher Bronk Ramsey, Martin Butzin, et al.

2020 The IntCal20 Northern Hemisphere Radiocarbon Age Calibration Curve (0-55 cal kBP). Radiocarbon 62:725-757.

Ritzenthaler, Robert E.

1954 A Comment on the Carbon-14 Dates for Old Copper. Wisconsin Archeologist 35(4):81.

1970 Another Radiocarbon Date for the Oconto Site. Wisconsin Archeologist 51(2):77.

Ritzenthaler, Robert E., Neil Ostberg, Kirk Whaley, Martin Greenwald, Penny Foust, Ernest Schug, Warren Wittry, Heinz Meyer, and Edward Lundsted 
1957 Reigh Site Report No. 3. Wisconsin Archeologist 38(4):278-310.

Ritzenthaler, Robert E., and Warren L. Wittry

1952 The Oconto Site, an Old Copper Manifestation. Wisconsin Archeologist 33(4):199-223.

Ritzenthaler, Robert E. (editor)

1957 The Old Copper Culture of Wisconsin. Wisconsin Archeologist 38(4): 186-329.

Rivadeneira, Marcelo M., Gene Hunt, and Kaustuv Roy 2009 The Use of Sighting Records to Infer Species Extinctions: An Evaluation of Different Methods. Ecology 90:1291-1300.

Roberts, Benjamin W., and Christopher P. Thornton (editors) 2014 Archaeometallurgy in Global Perspective: Methods and Syntheses. Springer Science \& Business Media, Berlin.

Roberts, Benjamin W., Christopher P. Thornton, and Vincent C. Pigott

2009 Development of Metallurgy in Eurasia. Antiquity 83:1012-1022.

Roberts, David L. and Andrew R. Solow

2003 When Did the Dodo Become Extinct? Nature 426:245.

Salzer, Robert J.

1974 The Wisconsin North Lakes Project: A Preliminary Report. In Aspects of Upper Great Lakes Prehistory: Papers in Honor of Lloyd A. Wilford, edited by Elden Johnson, pp. 40-54. Minnesota Prehistoric Archaeology Series 11. Minnesota Historical Society, St. Paul.

Scerri, Eleanor M. L.

2012 A New Stone Tool Assemblage Revisited: Reconsidering the "Aterian" in Arabia. Proceedings of the Seminar for Arabian Studies 42:357-369.

Schillinger, Kerstin, Alex Mesoudi, and Stephen J. Lycett

2014 Copying Error and the Cultural Evolution of "Additive" vs. "Reductive" Material Traditions: An Experimental Assessment. American Antiquity 79:128-143.

Shay, Thomas C.

1971 The Itasca Bison Kill Site: An Ecological Analysis. Minnesota Prehistoric Archaeology Series 6. Minnesota Historical Society, St. Paul.

Solow, Andrew R.

1993 Inferring Extinction from Sighting Data. Ecology 74:962-964.

2005 Inferring Extinction from a Sighting Record. Mathematical Biosciences 19(1):47-55.

Speth, John D.

2020 Paleoindian Bison Hunting on the North American Great Plains-Two Critical Nutritional Constraints. PaleoAnthropology 2020:74-97.
Steinbring, Jack

1966 Old Copper Culture Artifacts in Manitoba. American Antiquity 31:567-574.

1968 A Copper Blade of Possible Paleo-Indian Type. Manitoba Archaeological Newsletter 5(1-2):3-12.

1970 Evidences of Old Copper in a Northern Transition Zone. In Ten Thousand Years: Archaeology in Manitoba, edited by Walter M. Hlady, pp. 47-75. Manitoba Archaeological Society, Winnipeg.

1975 Taxonomic and Associational Considerations of Copper Technology during the Archaic Tradition. PhD dissertation, Department of Anthropology, University of Minnesota, Minneapolis.

1991 Early Copper Artifacts in Western Manitoba. Manitoba Archaeological Quarterly 1(1):25-61.

Stuiver, Minze, and Paula J. Reimer

1993 Extended ${ }^{14} \mathrm{C}$ Data Base and Revised CALIB 3.0

${ }^{14} \mathrm{C}$ Age Calibration Program. Radiocarbon 35:215230.

Trotter, Katherine E.

2017 A Matter of Suspension: An Experimental Approach to Hammerstone Hafting in Prehistoric Keweenaw Copper Mining. Master's thesis, Department of Anthropology, University of Wisconsin, Milwaukee.

Vernon, William W.

1990 New Archaeometallurgical Perspectives on the Old Copper Industry of North America. In Geological Society of America Centennial Special, Vol. 4, edited by Norman P. Lasca and Jack Donahue, pp. 499-512. Geological Society of North America, Boulder, Colorado.

Wittry, Warren L., and Robert E. Ritzenthaler

1956 The Old Copper Complex: An Archaic Manifestation in Wisconsin. American Antiquity 21:244-254.

1957 The Old Copper Complex: An Archaic Manifestation in Wisconsin. Wisconsin Archeologist 38(4): 311-328.

Yalçın, Ünsal

2017 The Beginnings of Metal Use in West Asia. In Ancient West Asian Civilization: Geoenvironment and Society in Pre-Islamic Middle East, edited by Akira Tsuneki, Shigeo Yamada, and Ken-ichiro Hisada, pp. 115-130. Springer, Singapore.

Zhang, Hui, Ivan Jarić, David L. Roberts, Yongfeng He, Hao $\mathrm{Du}$, Jinming Wu, Chengyou Wang, and Qiwei Wei

2020 Extinction of One of the World's Largest Freshwater Fishes: Lessons for Conserving the Endangered Yangtze Fauna. Science of the Total Environment 710:136242. DOI:10.1016/j.scitotenv.2019.136242.

Submitted March 23, 2021; Revised May 19, 2021; Accepted June 21, 2021 